\title{
An unusual branching of the axis artery of human upper limb - a morphological case report
}

\author{
PAI, M. M. ${ }^{1}$, SHENOY, V. ${ }^{2}$, PRABHU, P. D. ${ }^{3}$, \\ MURLIMANJU, B. V. $^{1}{ }^{*}$ and PRABHU, L. V. ${ }^{1}$ \\ ${ }^{1}$ Department of Anatomy, Kasturba Medical College, Manipal University, CEP 576104, Mangalore, India \\ ${ }^{2}$ Department of Anatomy, Savitha Medical College, CEP 600072, Chennai, India \\ ${ }^{3}$ Department of Anatomy, Ross University School of Medicine, Picard, CEP 2300, \\ Common Wealth of Dominica, West Indies \\ ${ }^{*}$ E-mail: flutesnowmm@gmail.com
}

\begin{abstract}
Introduction: During the development, 7th cervical intersegmental artery would lead to the axis artery. Axis artery is the major artery from which all other branches of the upper limb arteries arise. Materials and Methods: In the present case, variation in the branching pattern of the axis artery of upper limb was observed in an adult male cadaver. Results: There was an additional branch arising from the brachial artery and it was running in the forearm. As usual, the brachial artery bifurcated into ulnar and radial arteries. Conclusions: The knowledge of variations reported here is important to the operating surgeons and radiologists.
\end{abstract}

Keywords: axis artery, brachial artery, median artery, variation.

\section{Introduction}

The vascular anatomy is the most inconstant one in the human body. Variations in the arterial pattern of the upper limb are frequently encountered and it was reported that these variations are significant clinically and surgically (BATAINEH, AL-HUSSAIN and MOQATTASH, 2007; BHAT, POTU and GOWDA, 2008; YANG, GIL, JUNG et al., 2008). Awareness of these variations is necessary to avoid complications during radio diagnostic procedures and surgeries of the upper limb (YANG, GIL, JUNG et al., 2008; CHERIAN, NAYAK and SOMAYAJI, 2009). Diversions from the typical anatomical arterial pattern of the upper limb have an incidence of up to $20 \%$ (NATSIS, PAPADOPOULOU, PARASKEVAS et al., 2006). Such variations are usually the result of unusual formation of blood vessels during the development. Developmentally the 7 th cervical intersegmental artery gives rise to the axis artery which forms the major artery from which other branches of the upper limb arteries arise. The proximal portion of axis artery above the level of teres major forms the axillary artery and distally it continues as brachial artery, and finally in the cubital fossa, as the interosseous artery. A median artery develops later from the anterior interosseous artery and grows along the median nerve to communicate with the palmar capillary plexus. Close to the bend of the elbow, the axis artery gives rise to radial and ulnar artery. The radial and ulnar arteries arise late in the development, because of the interosseous artery becomes reduced in size. The ulnar artery then communicates with superficial palmar arch and the radial artery communicates with the deep palmar arch and this is followed by regression of median artery. In the present case, we observed an unusual branching pattern of the arteries of the upper limb. This might be due to developmental variation in the branching pattern of the axis artery.

\section{Case Report}

During the routine dissection procedure performed for the undergraduate medical students in our institution, we encountered variations of arteries in the right upper limb of an adult male cadaver. It was observed that the brachial artery gave an additional branch (Figure 1), which was about $10 \mathrm{cms}$ proximal to the medial epicondyle. This additional artery ran distally and followed the median nerve in the arm. Additional artery and the median nerve were seen to pierce the humeral head of pronator teres (Figure 1) and entered the cubital fossa. Beyond this, the median nerve had a normal course. The additional artery in the cubital fossa gave anterior and posterior ulnar recurrent arteries and then gave off posterior interosseous artery (Figure 2). After that it followed the course of anterior interosseous artery along with anterior interosseous nerve. The brachial artery proper bifurcated about $2-3 \mathrm{~cm}$ above the elbow. Both the ulnar and radial arteries were found to be of equal caliber and were superficial. The ulnar artery was passing superficial to the flexor retinaculum and the radial artery also followed the normal course.

\section{Discussion}

The brachial artery bifurcates at the level of neck of radius into radial and ulnar arteries. It is wholly superficial, covered anteriorly only by the skin, superficial and deep fasciae. The radial artery descends along the lateral side of the forearm, from the medial side of the neck of the radius to the wrist. The ulnar artery courses through the medial side of the forearm. The common interosseous artery is a short branch of the ulnar artery, which divides into the anterior and posterior interosseous arteries at the proximal border of the interosseous membrane. The anterior interosseous artery descends on the anterior aspect of the 


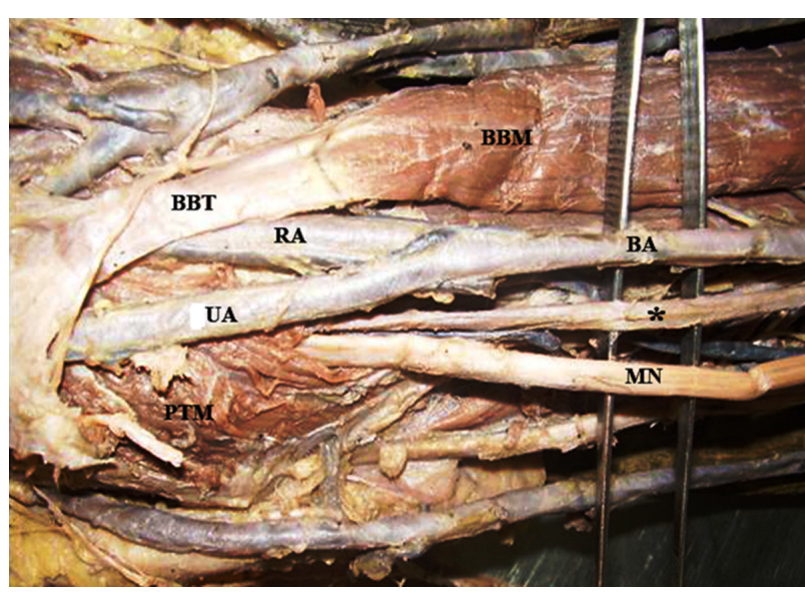

Figure 1. Photograph showing the additional branch arising from the brachial artery in the arm and running in the forearm (BA-brachial artery; ${ }^{*}$-additional branch arising from the brachial artery; UA-ulnar artery; RA-radial artery; MN-median nerve; BBM-biceps brachii muscle; BBT-biceps brachii tendon; PTM-pronator teres muscle). Additional artery and the median nerve were piercing the humeral head of pronator teres and entered the cubital fossa.

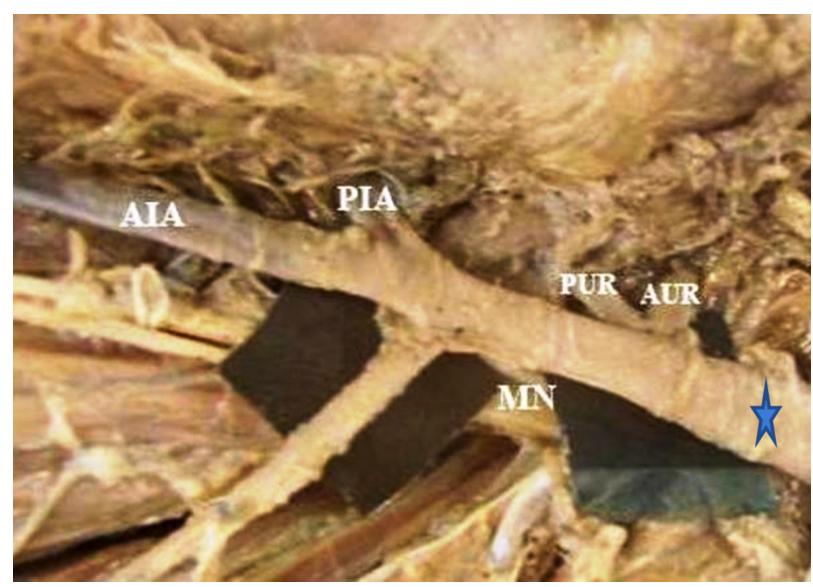

Figure 2. Photograph showing the branching pattern of the additional artery which was arising from the brachial artery ( ${ }^{*}$-additional artery arising from the brachial artery; AURanterior ulnar recurrent artery; PUR-posterior ulnar recurrent artery; MN-median nerve; PIA-posterior interosseous artery; AIA-anterior interosseous artery).

interosseous membrane, pierces the interosseous membrane proximal to pronator quadratus and anastomoses with the posterior interosseous artery in the posterior compartment of the forearm (STANDRING, 2008). There are few cases reported in the literature about the superficial ulnar artery. The superficial ulnar artery is defined as an ulnar artery which branches from the axillary, brachial or superficial brachial arteries, courses over the forearm flexor muscles and coexists with a brachial or superficial brachial artery that branches into either the radial and common interosseous arteries or, less frequently, into the radial and ulnar arteries. Presence of a superficial ulnar artery seems to be a rare variation with the incidence of $0.7 \%-9.4 \%$ in the literature (BHAT, POTU and GOWDA, 2008). The superficial ulnar artery may replace the ulnar artery altogether or it may supplement it. In our case, the additional branch of the brachial artery was similar to the superficial ulnar artery and it followed its normal course.

Persistence of a median artery is not uncommon in an adult and is considered to be a retained primitive arterial pattern. The reported incidence ranges from 2.2-4.4\% (ARIFOGLU, SEVINC, BARUT et al., 2008). Two patterns of median artery termination have been described: forearm type, in which the artery does not reach the hand and the palmar type, which is variable, the artery may terminate either in a closed arch (medianoulnar or radiomedianoulnar) or in an incomplete one. In the latter pattern, the artery continues either as the 2 nd common palmar digital artery or divides into first two common palmar digital arteries (SANUDO, CHIKWE and EVANS, 1994). In the present case the median artery continued as the anterior interosseous artery and took part in the formation of the posterior carpal arch. Ramanathan, Nayak, Vinay et al. (2009) reported a case of superficial brachio-ulno-radial type of arterial pattern which was associated with a palmar type of persistent median artery. They noted the presence of a superficial brachial artery which divided into superficial radial and ulnar arteries. The superficial ulnar artery was found terminating in the palm to form superficial palmar arch. In the clinical scenario, a persistent median artery may be used as a graft artery elsewhere in the body, if present (FUMIERE, DUGARDEYN, ROQUET et al., 2002; YANG, GIL, JUNG et al., 2008; ARIFOGLU, SEVINC, BARUT et al., 2008; CHERIAN, NAYAK and SOMAYAJI, 2009). Fumiere, Dugardeyn, Roquet et al. (2002) reported a case of a 39-year-old man, who presented with sudden onset of cramping pain involving the radial aspect of his left hand and extending into the index and the middle fingers. On examination they found the minor swelling of the palmar aspect of the distal left forearm. On Doppler examination, it was diagnosed as the presence of a left persistent median artery with a distal thrombosis. Superficial course of the persistent median artery close to the flexor retinaculum may damage the blood supply of the hand during excision. When it is much enlarged and thrombosed it may compress the median nerve and cause symptoms of carpal tunnel syndrome. Bataineh, Al-Hussain and Moqattash (2007) also reported the presence of a persistent median artery arising from the ulnar artery, $5 \mathrm{~cm}$ below the intercondylar line and continuing deep to the flexor retinaculum and terminating in the hand as princeps pollicis and radialis indicis arteries. Bhat, Potu and Gowda (2008) also reported a similar case where the ulnar artery was found superficial all along its course and in the hand they found it anastomosing with the radial artery to form the superficial palmar arch. But they found the ulnar artery to be arising from the axillary artery at the level of the junction of the two roots of median nerve. They noted the axillary artery further continuing as brachial artery and dividing into radial and common interosseous arteries in the cubital fossa.

According to Natsis, Papadopoulou, Paraskevas et al. (2006), the presence of a superficial ulnar artery may be due to haemodynamic forces, chemical factors, foetal position in the uterus, fetal limb movements, and developmental arrest in the early stages and genetic predisposition. Superficial position of the ulnar artery makes it more vulnerable to trauma and thus hemorrhages. It also has a high risk of getting damaged during the forearm surgeries. Also a superficial artery can be easily mistaken for a vein. Such misinterpretation may cause damage to the artery in intravenous injections and cause difficulties 
in angiographic procedures (NATSIS, PAPADOPOULOU, PARASKEVAS et al., 2006; BHAT, POTU and GOWDA, 2008; CHERIAN, NAYAK and SOMAYAJI, 2009). Considering these possible complications and benefits, investigations of the arterial pattern in patient upper limbs before any invasive procedures might be helpful in avoiding the iatrogenic injury. We believe that the knowledge of variations reported here is important to the operating orthopedic and plastic surgeons, radiologists and nurses.

\section{References}

ARIFOGLU, Y., SEVINC, O., BARUT, C., IS, M. and DIRAMALI, M. Persistent median artery: case report and review of the literature. Sinir Sistemi Cerrahisi Dergisi, 2008, vol. 1, n. 3, p. 195-198.

BATAINEH, ZM., AL-HUSSAIN, SM. and MOQATTASH, ST. Complex neurovascular variation in one upper limb. Italian Journal of Anatomy and Embryology, 2007, January-March., vol. 112, n. 1, p. 37-44. PMid:17580659.

BHAT, KM., POTU, BK. and GOWDA, S. High origin of ulnar artery in South Indian male cadaver: a case report. Romanian Journal of Morphology and Embryology, 2008, vol. 49, n. 4, p. 573-575. PMid:19050810.

CHERIAN, SB., NAYAK, SB. and SOMAYAJI, N. Superficial course of brachial and ulnar arteries and high origin of common interosseous artery. International Journal of Anatomical Variations, 2009, vol. 2, p. 4-6.
FUMIERE, E., DUGARDEYN, C., ROQUET, ME. and DELCOUR, C. US demonstration of a thrombosed persistent median artery in carpal tunnel syndrome. Journal belge de radiologie Belgisch tijdschrift voor radiologie, 2002, vol. 85, n. 1, p. 1-3.

NATSIS, K., PAPADOPOULOU, AL., PARASKEVAS, G., TOTLIS, T. and TSIKARAS, P. High origin of a superficial ulnar artery arising from the axillary artery: anatomy, embryology, clinical significance and a review of the literature. Folia Morphologica, 2006, November, vol. 65 , n. 4, p. 400-405. PMid:17171623.

RAMANATHAN, L., NAYAK, SR., VINAY, KV., KRISHNAMURTHY, A. and PRABHU, LV. Co-existence of superficial brachio-ulnoradial arterial pattern and persistent median artery. Indian Journal of Plastic Surgery, 2009, January-June, vol. 42, n. 1, p. 112-114. http://dx.doi.org/10.4103/0970-0358.53021. PMid:19881031.

SANUDO, J., CHIKWE, S. and EVANS, E. Anomalous median nerve associated with persistent median artery. Journal of Anatomy, 1994, vol. 185, (Pt 2), p. 447-451.

STANDRING, S. Gray's Anatomy: the anatomical basis of clinical practice. 39th ed. Elsevier: Churchill Livingstone, 2008. p. 1266-1274.

YANG, HJ., GIL, YC., JUNG, WS. and LEE, HY. Variations of the superficial brachial artery in Korean cadavers. Journal of Korean Medical Science, 2008, October, vol. 23, n. 5, p. 884-887. http:// dx.doi.org/10.3346/jkms.2008.23.5.884. PMid:18955798.

Received March 1, 2014 Accepted July 8, 2015 